\title{
A 55 kDa hypothetical membrane protein is an iron- regulated virulence factor of Francisella tularensis subsp. novicida U112

\begin{abstract}
Correspondence
Timothy S. Milne

TSMILNE@dstl.gov.uk
\end{abstract} \\ Received 26 January 2007 \\ Accepted 13 June 2007

\author{
Timothy S. Milne, ${ }^{1}$ Stephen L. Michell, ${ }^{1} \dagger$ Helen Diaper, ${ }^{1}$ Per Wikström, ${ }^{2}$ \\ Kerstin Svensson, ${ }^{2}$ Petra C. F. Oyston ${ }^{1,3}$ and Richard W. Titball ${ }^{1,4} \dagger$ \\ ${ }^{1}$ Defence Science and Technology Laboratory, Porton Down, Salisbury SP4 OJO, UK \\ ${ }^{2}$ Swedish Defence Research Agency, SE-901 82 Umeå, Sweden \\ ${ }^{3}$ Department of Infection, Immunity and Inflammation, Maurice Shock Building, University of \\ Leicester, PO Box 138, Leicester LE1 9HN, UK \\ ${ }^{4}$ Department of Infectious and Tropical Diseases, London School of Hygiene and Tropical Medicine, \\ Keppel Street, London WC1E 7HT, UK
}

\begin{abstract}
Iron is an important nutritional requirement for bacteria due to its conserved role in many essential metabolic processes. As a consequence of the lack of freely available iron in the mammalian host, bacteria upregulate a range of virulence factors during infection. Transcriptional analysis of Francisella tularensis subsp. novicida U112 grown in iron-deficient medium identified 21 genes upregulated in response to this condition, four of which were attributed to a siderophore operon. In addition, a novel iron-regulated gene, FTT0025, was identified which is part of this operon and encodes a $55 \mathrm{kDa}$ hypothetical membrane protein. When grown on chrome azurol $\mathrm{S}$ agar, the F. tularensis subsp. novicida U112 2 FTT0025 mutant produced an increased reaction zone compared with the wild-type, suggesting that siderophore production was unaffected but that the bacteria may have a deficiency in their ability to re-sequester this iron-binding molecule.

Furthermore, the $\triangle F T T 0025$ mutant was attenuated in a BALB/c mouse model of infection relative to wild-type F. tularensis subsp. novicida U112.
\end{abstract}

\section{INTRODUCTION}

The onset of infection by pathogenic bacteria is usually achieved by invading and colonizing a particular host niche. Initially, a primary goal for invading cells is obtaining essential metabolites to promote successful bacterial replication. As iron is an essential nutrient, due in part to its conserved role in many vital microbial cellular processes (Wooldridge \& Williams, 1993), iron acquisition is viewed as an important virulence trait for many bacterial pathogens. However, several paradoxical issues relate to the general acquisition and utilization of iron by biological systems. Firstly, although iron is the most abundant transition metal, its availability is restricted by the formation of insoluble ferric hydroxide under aerobic physiological conditions (Andrews, 1998). Furthermore, oxidative metabolism of free iron can form toxic hydroxyl radicals, which pose a threat to core cellular molecules (Halliwell \& Gutteridge, 1984). Therefore, iron atoms are commonly solubilized and

tPresent address: School of Biosciences, Geoffrey Pope Building, University of Exeter, Exeter EX4 4OD, UK.

Abbreviations: CAS, chrome azurol S; LVS, live vaccine strain; MLD, median lethal dose; s.c., subcutaneous. maintained in vivo by incorporation into specific ironbinding proteins (Clarke et al., 2001), thus restricting the availability of host iron to potential invading organisms. To counteract the iron-restricted host status, microbes can quickly adapt to this environmental cue by triggering the increased expression of specific virulence-associated mechanisms such as iron acquisition, via tightly regulated feedback (Litwin \& Calderwood, 1993). One commonly deployed bacterial iron-acquisition mechanism is the production of a siderophore, a high-affinity iron-chelating molecule that can acquire iron from host iron-binding proteins including transferrin and lactoferrin. Following secretion, siderophores bind host iron and are transported back into the bacteria via cell-surface receptor-mediated uptake (Ratledge \& Dover, 2000). Siderophores have been identified in many human pathogenic species, including Pseudomonas, Burkholderia, mycobacteria and Salmonella (Crosa, 1997; De Voss et al., 1999; Ratledge \& Dover, 2000).

The Gram-negative coccobacillus Francisella tularensis is an endemic zoonotic pathogen and the causative agent of the debilitating disease tularaemia (Johansson et al., 2000; Petersen \& Schriefer, 2005). Of the four described $F$. tularensis subspecies, F. tularensis subsp. tularensis is 
considered the most infectious for humans with an $\mathrm{LD}_{50}$ of $<10$ c.f.u. delivered via the subcutaneous (s.c.) route (Gurycova, 1998). This subspecies is recognized as a cause for concern by the World Health Organization as a potential biological weapon (Casadevall \& Pirofski, 2004). The least-virulent subspecies for humans is the rarely isolated F. tularensis subsp. novicida (Whipp et al., 2003), although analysis of rRNA sequences has suggested a high degree of similarity at the genetic level amongst the different F. tularensis subspecies (Forsman et al., 1994). The genetic relatedness of the subspecies enables lessvirulent subspecies to serve as models for investigation of Francisella with less risk to laboratory personnel. Two recent independent Francisella studies highlighted a fourgene operon that was responsible for siderophore biosynthesis, positioned directly downstream of the fur global iron-regulator gene (Deng et al., 2006; Sullivan et al., 2006). The aims of this study were to confirm that FTT0025, an additional gene adjacent to this novel Francisella operon, is also involved in siderophore functionality and to examine the effects of deleting this gene on the virulence of F. tularensis subsp. novicida U112. (FTT0025 has been used as the designation of the gene reported in this study in accordance with the F. tularensis subsp. tularensis SchuS4 annotation, although this gene has been denoted FTN_1686 in the recently released $F$. tularensis subsp. novicida U112 annotation.)

\section{METHODS}

Bacterial strains and culture media. All bacterial strains and plasmids used are described in Table 1. F. tularensis subsp. novicida U112 was routinely cultured in Chamberlain's defined medium (CDM) (Chamberlain, 1965) at $37{ }^{\circ} \mathrm{C}$ with aeration. CDM was produced in sterile plasticware to prevent contamination with trace levels of iron, and was filter-sterilized (Nalgene $500 \mathrm{ml}$ capacity, pore size $0.2 \mu \mathrm{m}$ ) prior to storage at $2-8{ }^{\circ} \mathrm{C}$ for 1 month. For ironlimitation experiments, $\mathrm{CDM}$ was prepared without $\mathrm{FeSO}_{4} \cdot 7 \mathrm{H}_{2} \mathrm{O}$. To ensure further elimination of trace iron, filter-sterilized deferoxamine was added to pre-warmed media prior to use, giving a final concentration of $10 \mu \mathrm{M}$. Blood cysteine glucose agar (BCGA) plates containing $4 \%(\mathrm{w} / \mathrm{v})$ cysteine, $4 \%(\mathrm{w} / \mathrm{v})$ histidine, $5 \%(\mathrm{w} / \mathrm{v})$ glucose and $10 \%(\mathrm{v} / \mathrm{v})$ horse blood were used for plating out serial dilutions when determining $F$. tularensis subsp. novicida U112 culture cell counts and purity. Modified Thayer-Martin agar plates [100 ml GC agar base, $100 \mathrm{ml}$ defibrinated horse blood, $1 \%(\mathrm{w} / \mathrm{v})$ IsoVitalex, $100 \mu \mathrm{g}$ polymyxin $\mathrm{B} \mathrm{ml} \mathrm{m}^{-1}$ and $20 \mu \mathrm{g}$ chloramphenicol $\mathrm{ml}^{-1}$ ] were incubated at $37{ }^{\circ} \mathrm{C}$ for $24-72 \mathrm{~h}$ for the selection of F. tularensis subsp. novicida U112 integrants. Mutants were counter-selected by streaking colonies onto modified chloramphenicol-free Thayer-Martin agar supplemented with $5 \%(\mathrm{w} / \mathrm{v})$ sucrose. All Escherichia coli strains were grown in Luria-Bertani medium at $37{ }^{\circ} \mathrm{C}$.

Iron-replete and iron-deficient growth of $\boldsymbol{F}$. tularensis subsp. novicida U112. An overnight $F$. tularensis subsp. novicida U112 culture was prepared by inoculating $20 \mathrm{ml} \mathrm{CDM}$ with approximately $3 \times 10^{9}$ cells and cultured to an $\mathrm{OD}_{600}$ of 1.9 . Bacteria were then subcultured into a $30 \mathrm{ml}$ total volume of pre-warmed CDM to a

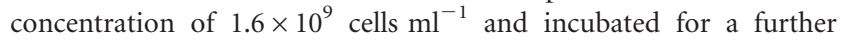
$2.5 \mathrm{~h}$. Cells were washed three times with PBS and resuspended in $30 \mathrm{ml}$ pre-warmed $\mathrm{CDM}$ or $10 \mu \mathrm{M}$ deferoxamine-supplemented $\mathrm{CDM}$ without $\mathrm{FeSO}_{4} \cdot 7 \mathrm{H}_{2} \mathrm{O}$ to a density of $4.5 \times 10^{7}$ cells $\mathrm{ml}^{-1}$. At $T_{0}$, and every subsequent hour, $1 \mathrm{ml}$ of culture was removed and the $\mathrm{OD}_{600}$ was measured. This experiment was repeated three separate times for the construction of accurate growth curves.

Nucleic acid isolation. RNA extraction was carried out using an RNeasy midi preparation kit (Qiagen) following treatment of approximately $4 \times 10^{9}$ c.f.u. with 2 vols RNAProtect bacterial reagent (Qiagen). RNA quantification was performed by spectrophotometric analysis using a NanoDrop ND-1000 (NanoDrop Technologies) and each RNA sample was adjusted to give a final concentration of $1 \mu \mathrm{g} \mu \mathrm{l}^{-1}$.

All genomic DNA preparations were isolated using a Puregene DNA Isolation kit (Gentra Systems) and plasmid DNA was isolated using a PerfectPrep kit (Eppendorf), both according to the manufacturer's instructions.

Production of a Francisella-specific DNA microarray. A microarray containing 1937 F. tularensis subsp. tularensis SchuS4

Table 1. Bacterial strains and plasmids used in this study

\begin{tabular}{|c|c|c|}
\hline Strain/plasmid & Description & Source \\
\hline \multicolumn{3}{|l|}{ Strains } \\
\hline \multicolumn{3}{|l|}{ Escherichia coli } \\
\hline S17- $\lambda$ pir & $\begin{array}{l}\text { Host strain used for transfer of suicide plasmid into F. tularensis subsp. novicida U112 by } \\
\text { conjugation }\end{array}$ & This study \\
\hline \multicolumn{3}{|l|}{ F. novicida } \\
\hline U112 $\Delta$ FTT0025 & F. tularensis subsp. novicida U112 with unmarked in-frame deletion of FTT0025 & This study \\
\hline \multicolumn{3}{|l|}{ Plasmids } \\
\hline pGEM-T Easy Vector System I & Cloning vector; $\mathrm{Amp}^{\mathrm{R}}$ & Promega \\
\hline pTM6a & pGEM-T containing 1274 bp FTT0025 left flanking region & This study \\
\hline pTM7a & pGEM-T containing 1074 bp FTT0025 right flanking region & This study \\
\hline рTM8 & pGEM-T containing PCR product of 2337 bp $\triangle F T T 0025$ left and right flanking regions & This study \\
\hline
\end{tabular}


ORFs with a minimum size of $120 \mathrm{bp}$ was constructed. This was based on ORF predictions from a concatenated version of the pre-annotated genome, obtained using GLIMMER and GLIMMER2 software. Each ORF was represented by one 50-mer oligonucleotide, designed and optimized by MWG Biotech. The array also contained control spots comprising 20 ORFs from 10 unrelated organisms. Arrays were printed on Nexterion A glass slides (SCHOTT Glass), coated with aminosilane, using a Biorobotics TAS Microgrid II Arrayer (Genomics Solutions). Each oligonucleotide was printed twice on each array, and the entire array was printed twice on each slide to give a total of four replicate spots per oligonucleotide. Oligonucleotides were fixed to the slides by baking in a dry oven at $180{ }^{\circ} \mathrm{C}$ for $2 \mathrm{~h}$.

Microarray labelling reactions. Reverse transcription and incorporation of $\mathrm{Cy} 3-\mathrm{dCTP}$ or $\mathrm{Cy} 5-\mathrm{dCTP}$ fluorescent dye during cDNA synthesis from $F$. tularensis subsp. novicida U112 RNA was performed as described previously (Stewart et al., 2002), with the exception that CyScript reverse transcriptase (GE Healthcare) was used in place of Superscript II. To enable a reference design experiment, $F$. tularensis subsp. tularensis SchuS4 genomic DNA was used as a background control for each slide, enabling global scaling during data analysis. For every RNA sample, a dye swap experiment was performed.

Microarray hybridization. Test and control Cy3/Cy5-labelled samples were mixed, co-purified using a MinElute DNA purification kit (Qiagen) and eluted into $10 \mu \mathrm{l} \mathrm{dH}_{2} \mathrm{O}$, to which $10 \mu \mathrm{l} 1 \times$ DIG Easy Hyb buffer (Roche) was added, followed by heating at $95{ }^{\circ} \mathrm{C}$ for $2 \mathrm{~min}$. A $22 \times 22 \mathrm{~mm}$ LifterSlip (Erie Scientific) was placed over each slide, under which $20 \mu \mathrm{l}$ co-purified, labelled DNA was pipetted. Hybridization was performed by incubating the slides in sealed chambers at $42{ }^{\circ} \mathrm{C}$ overnight. After removing the coverslip, slides were then immersed in pre-warmed FT1 washing buffer $(50 \mathrm{ml} 20 \times$ SSC, $25 \mathrm{ml} 10 \%$ SDS, $425 \mathrm{ml} \mathrm{dH}_{2} \mathrm{O}$ ) for two separate 15 min washes at $42{ }^{\circ} \mathrm{C}$ with gentle rotation. This process was repeated with FT2 washing buffer $(6.25 \mathrm{ml} 20 \times$ SSC, $25 \mathrm{ml} 10 \%$ SDS, $468.75 \mathrm{ml}$ $\mathrm{dH}_{2} \mathrm{O}$ ). The microarray slides were dried by centrifugation at $257 \mathrm{~g}$ for $7 \mathrm{~min}$ and stored in the dark until scanning.

Microarray analysis. Each microarray slide was scanned in the $\mathrm{Cy} 3$ channel $(510-550 \mathrm{~nm})$ and Cy5 channel (630-660 nm) using a GenePix 4000B scanner and GENEPIX PRO software (Molecular Devices Corporation). The resultant TIFF digital image files were quantified using BLUEFUSE v3.1 software (BlueGnome) and saved as Excel 97 output files. To determine the most appropriate form of normalization, MA plots were constructed for each corresponding iron-replete/ iron-deficient dataset for a given time point and replicate. From the data scatter pattern observed from these plots, linear normalization was then applied individually to each separate dataset. For this, quality control was performed by excluding positive- and negativecontrol gene spots from each dataset, as well as those with confidence values $<0.1$ (denoted in BLUEFUSE by confidence flag E). A normalizing constant, defined as the median channel $1 /$ channel 2 $\log _{2}$ ratio across all probes for a given array, was then calculated and subtracted from each probe $\log _{2}$ ratio. After global scaling, the relative gene expression for each time point was determined by calculating the mean $\log _{2}$ ratio difference across each paired iron-replete and irondeficient dataset. To test the expression levels statistically, a significance $P$ value was determined using a paired two-tailed $t$-test, and the Benjamini-Hochberg procedure for controlling false discovery rate was applied. Fold change levels were calculated for each gene, with those showing upregulation of $\geqslant 1.5$-fold under irondeficient growth considered biologically relevant.

RT-PCR. Oligonucleotide primers (25-mers) were designed for amplification of the FTT0025 gene (forward: $5^{\prime}$-AGCAAGGTATAACCCAACTACAATC-3'; reverse: 5' -TGCGCGTTGTGAGGAAACTATAATC-3') and a region spanning FTT0025 and FTT0026 (forward:
5' -CACCTACTTGGAGCCGCCATATGTG-3'; reverse: 5' -CAAACCAAAGCTGCGCATCAGCTTC-3') using CLONE MANAGER software (Scientific and Educational Software). RNA was pre-treated with a Turbo DNA-free kit (Ambion) according to the manufacturer's instructions and reversed transcribed using an Enhanced Avian RT First Strand Synthesis kit (Sigma). PCR was performed in $20 \mu \mathrm{l}$ reactions containing $125 \mathrm{mM}$ dNTPs, $1 \mu \mathrm{M}$ oligonucleotides, $50 \mathrm{ng}$ cDNA, $2 \mu \mathrm{l}$ PCR buffer containing magnesium (Roche) and $0.1 \mu \mathrm{l}$ Taq polymerase. PCRs were performed under the following conditions: denaturation at $94{ }^{\circ} \mathrm{C}$ for $5 \mathrm{~min}$, followed by 30 cycles of $94{ }^{\circ} \mathrm{C}$ for $30 \mathrm{~s}, 55^{\circ} \mathrm{C}$ for $30 \mathrm{~s}$ and $72{ }^{\circ} \mathrm{C}$ for $1 \mathrm{~min}$, and a final elongation at $72{ }^{\circ} \mathrm{C}$ for $7 \mathrm{~min}$. The F. tularensis fopA gene was used as an internal control (forward: 5'-GGCCAGTGGTACTTAGGTGTAGATG-3'; reverse: 5'-GTATAGCACGCGACACCATCTTCAG-3'). Genomic DNA was included as a positive control, and $\mathrm{dH}_{2} \mathrm{O}$ and RNA controls were performed to exclude the possibility of DNA contamination. Band sizes were compared under UV light after samples had been electrophoresed through a $1 \%$ agarose gel.

Construction of a $\Delta$ FTT0025 mutagenesis plasmid. DNA manipulations were performed as described by Sambrook et al. (1989). The suicide plasmid for deletion of FTT0025 was constructed as follows. Regions of DNA flanking the FTT0025 gene were PCRamplified from $F$. tularensis subsp. novicida U112 genomic DNA using the primer pairs $\mathrm{P} 1 / \mathrm{P} 2$ and $\mathrm{P} 3 / \mathrm{P} 4$ (P1: 5'ATGCATGCCATTTCTTGCTGCCATTACTACCTTTAC-3'; P2: 5' $^{\prime}$ GACGTACGAAAGGGGGTAATTGATAATACTAAAAAG-3'; P3: 5' -TACGTACGACAATAGATATGGCTGTATATCTTTAAG-3'; P4: 5' CAGAGCTCGCATGCTAAGCCCAAATTAGGTAATCCA-3'; engineered restriction sites are underlined). The PCR products were cloned into the plasmid pGEM-T Easy (Promega) to give plasmids pTM6 and pTM7. These plasmids were digested with BsiWI and ligated. This ligation mixture was used as template in a PCR using the primer pair P1/P4. The product of $2337 \mathrm{bp}$ from this reaction was digested with SphI and cloned into pSMP62 [a gift from Dr S. Michell, Defence Science and Technology Laboratory, Porton Down, UK, derived from pSMP22 (Thomas et al., 2007), containing a BstEII chloramphenicol-resistance cassette], to generate pTM9. This resultant plasmid was electroporated into E. coli S17- $\lambda$ pir.

Conjugal transfer of plasmids. Allelic replacement by conjugation was performed based on the methods described by Golovliov et al. (2003). Transconjugants were selected on chloramphenicol-supplemented Thayer-Martin agar plates and merodiploids arising from chromosomal integration of the suicide plasmid were resolved by plating on Thayer-Martin agar supplemented with $5 \%$ (w/v) sucrose (Pelicic et al., 1996). Sucrose-resistant colonies were screened for the presence of a wild-type or mutant copy of FTT0025 by PCR using the primer pair P5 and P6 (P5: 5'-CAGCGGCAGTTGGCGTAGTATCACC-3'; P6: 5' -TACCGGTGCTATTACCAGGAGCAAC-3').

Southern blot hybridization. For Southern blot hybridization, EcoRV digests of 2-3 $\mu \mathrm{g}$ genomic DNA from $F$. tularensis subsp. novicida U112 wild-type and $\triangle F T T 0025$ mutant were separated by electrophoresis on a $1 \%$ agarose gel and transferred to a nylon membrane. The pTM6 insert was labelled with DIG-11-dUTP during PCR amplification with the primer pair $\mathrm{P} 1 / \mathrm{P} 2$ and used as a probe to hybridize to the membrane. DNA fragments to which the probe hybridized were detected in a chemiluminescent assay (CSPD substrate, $30 \mathrm{~min}$ exposure to X-ray film).

Growth of $F$. tularensis subsp. novicida U112 wild-type and $\Delta$ FTT0025 mutant in CDM. Volumes known to contain approximately $1.57 \times 10^{11}$ cells of $F$. tularensis subsp. novicida $\mathrm{U} 112$ wild-type and its isogenic $\triangle F T T 0025$ mutant were subcultured into $30 \mathrm{ml}$ fresh pre-warmed CDM. Incubation was carried out aerobically at $37{ }^{\circ} \mathrm{C}$ for $8 \mathrm{~h}$, with shaking at 180 r.p.m. At $T_{0}$, and each subsequent hour, 
$1 \mathrm{ml}$ culture was removed and the $\mathrm{OD}_{600}$ was measured. This experiment was repeated three times for the construction of accurate growth curves.

Chrome azurol S (CAS) assay. CAS-CDM agar plates were prepared as described previously (Deng et al., 2006). Standardized CDM suspensions of $F$. tularensis subsp. novicida U112 wild-type and its isogenic $\triangle F T T 0025$ mutant containing approximately $5 \times 10^{8}$ c.f.u. $\mathrm{ml}^{-1}$ were prepared as described previously. From these, $50 \mu \mathrm{l}$ was inoculated onto the centre of separate CAS-CDM plates. This procedure was performed in triplicate and plates were incubated at $37{ }^{\circ} \mathrm{C}$ for 3 days. At $24 \mathrm{~h}$ intervals, electronic callipers were used to measure the observable zone sizes (Machuca \& Milagres, 2003).

Attenuation study of $F$. tularensis subsp. novicida U112 $\Delta$ FTT0025 mutant. Challenge doses of $F$. tularensis subsp. novicida U112 wild-type and its isogenic $\triangle F T T 0025$ mutant were prepared by serially diluting cultures of approximately $10^{9}$ c.f.u. $\mathrm{ml}^{-1}$ (as determined by $\mathrm{OD}_{600}$ ). All challenges were prepared in PBS, and bacterial enumeration was confirmed by plating out onto BCGA plates. To investigate the level of attenuation, groups of six agematched (8-10-week-old) adult female BALB/c mice (Charles River) were challenged via the s.c. route. Mice showing obvious signs of distress were culled humanely. Significance of attenuation was determined by the Mantel-Haenszel log rank method using GRAPHPAD PRISM v4.0. The median lethal dose (MLD) of the $F$. tularensis subsp. novicida U112 2 FTT0025 mutant was calculated using the method of Reed \& Muench (1938). Virulence studies were carried out in accordance with legislative and welfare requirements and after prior authorization by an on-site ethics committee.

\section{RESULTS AND DISCUSSION}

\section{Growth restriction of $\boldsymbol{F}$. tularensis subsp. novicida U112 occurs in the absence of free iron}

The growth of bacteria in iron-deficient medium was used as a strategy to mimic the in vivo iron-restricted status of the host. As shown in Fig. 1, growth of wild-type F.

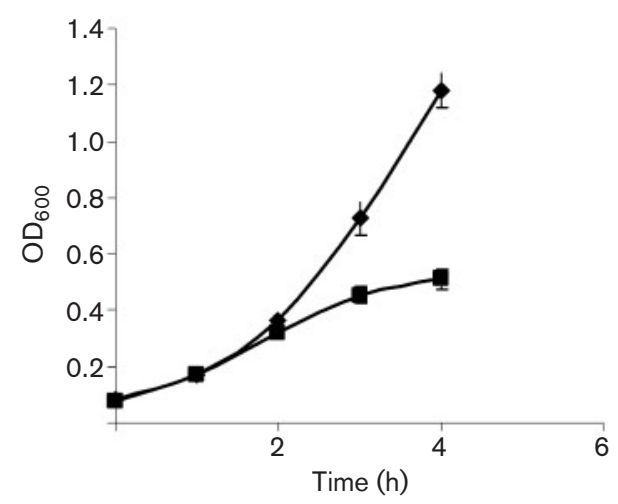

Fig. 1. Dependence of growth of $F$. tularensis subsp. novicida U112 on iron. Bacteria were cultured in iron-replete $(\lambda)$ or irondeficient ( $\boldsymbol{\square}$ ) CDM for $4 \mathrm{~h}$ as described in Methods. The data represent the mean of three separate experiments, with error bars indicating $95 \%$ confidence limits. tularensis subsp. novicida U112 was similar in iron-replete and iron-deficient media for up to approximately $2 \mathrm{~h}$. Subsequently, bacteria in iron-replete medium continued to grow exponentially, whilst bacteria in iron-deficient medium appeared to enter stationary phase. These results suggest that cells grown without a source of exogenous iron deplete their internal stores of iron within about $4 \mathrm{~h}$, after which growth ceases.

\section{Identification of a previously characterized $\boldsymbol{F}$. novicida subsp. novicida U112 iron-regulated operon}

As iron becomes limiting, cells are likely to express genes required to adapt to and survive this environment. To identify these genes in F. tularensis subsp. novicida U112, we examined gene expression at three separate time points during growth in iron-replete or iron-deficient medium. As described in Methods, a Francisella-specific DNA microarray was used to analyse RNAs expressed at 1,2 and $3.5 \mathrm{~h}$ of growth in the presence or absence of iron. Using a false discovery rate of 0.05 and focusing on changes in expression of $>1.5$-fold, 21 genes were identified as upregulated under iron-deficient conditions (data not shown). Four upregulated genes from this list (FTT0029, FTT0028, lysA and FTT0026) are positioned directly downstream of fur, the global iron regulator, indicating the presence of an iron-regulated operon (see Fig. 2). This observation is in good agreement with results reported in two recent publications that defined an iron-regulated operon present in both F. tularensis subsp. tularensis and the less-virulent F. tularensis subsp. holarctica and indicated that this operon is involved in siderophore biosynthesis (Deng et al., 2006; Sullivan et al., 2006). Sullivan and co-workers detected the presence of a siderophore in the culture filtrate of $F$. tularensis subsp. holarctica live vaccine strain (LVS) and F. tularensis subsp. tularensis SchuS4, and demonstrated that this operon was essential for siderophore biosynthesis, whilst Deng and colleagues employed microarray technology to study gene expression in LVS cultured under iron-replete or irondeficient conditions, identifying the same four-gene operon as the most highly upregulated genes in LVS when iron was limiting.

Within our microarray data was the novel observation that a fifth gene, FTT0025, a hypothetical membrane protein, located directly adjacent to FTT0026, was upregulated coordinately with the four genes of this operon. Expression of FTT0025 was upregulated 4.54 -fold $(P=0.08)$ at the $3.5 \mathrm{~h}$ time point. The data also suggested that FTT0025 expression was upregulated at $1 \mathrm{~h}(1.51$-fold, $P=0.68)$ and $2 \mathrm{~h}$ (3.10-fold, $P=0.11)$; however, these results did not achieve statistical significance. Neither Deng et al. (2006) nor Sullivan et al. (2006) identified FTT0025 as a member of the siderophore biosynthetic operon, and thus we undertook efforts to confirm the association of this gene with the operon. 


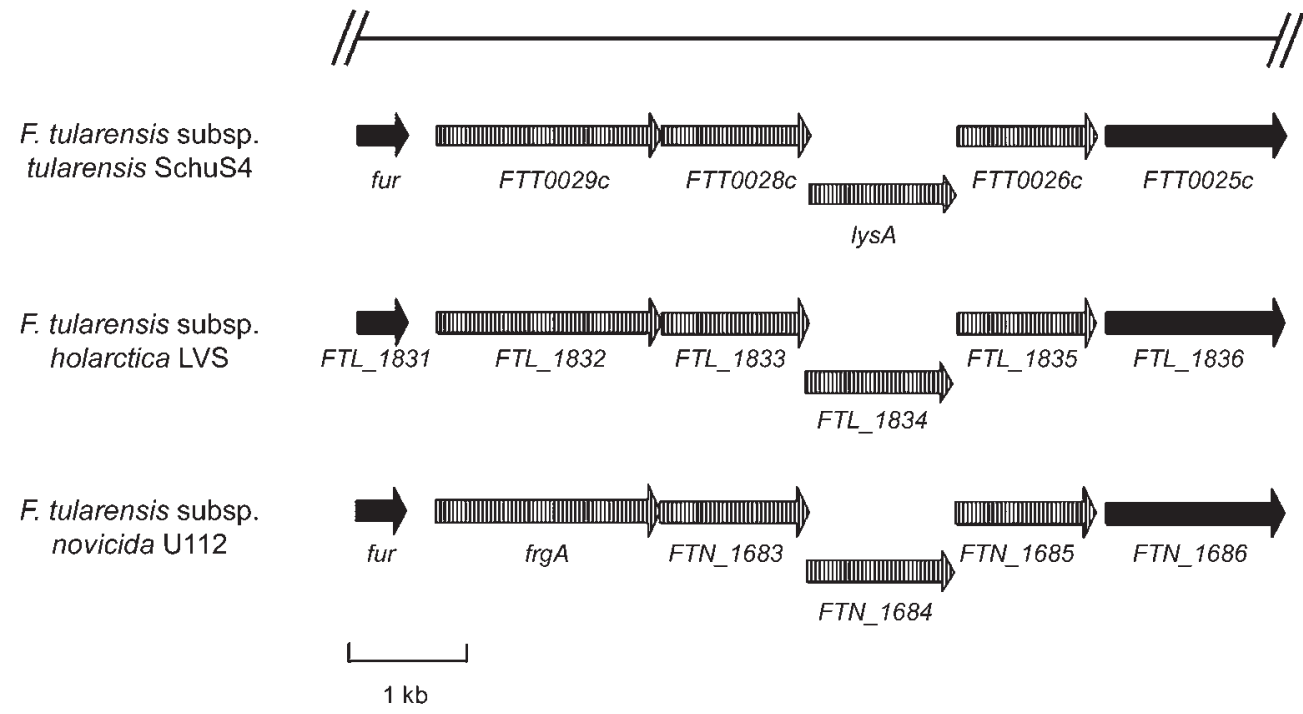

Fig. 2. Organization of the chromosome region containing an iron-regulated operon responsible for siderophore production in Francisella species. ORFs on the complementary DNA strand are indicated with a 'c'.

\section{Expression of FTT0025 is upregulated during iron deficiency}

To confirm the upregulation of FTT0025 expression, we employed RT-PCR as described in Methods. PCR primers were designed to amplify a $1301 \mathrm{bp}$ product of the FTT0025 gene. As an internal housekeeping control, primers were designed to amplify a $584 \mathrm{bp}$ PCR product of the fopA gene, an ORF whose expression is known to be unaffected by the amount of iron in the culture medium (Deng et al., 2006). The PCR results confirmed that FTT0025 was indeed upregulated by F. tularensis subsp. novicida U112 during iron-deficient growth (Fig. 3; compare lanes 4 and 5). The equal amounts of fopA product (Fig. 3; lanes 11 and 12) confirmed that equal masses of RNA were used in these reactions. The presence of RNA-negative controls ensured that no DNA contamination was present in the initial RNA samples after Turbo DNA-free treatment, whilst $\mathrm{H}_{2} \mathrm{O}$ negative controls confirmed that there was no DNA contamination in the PCR master mixes.

\section{FTT0025 is co-transcribed with the siderophore operon}

To determine whether FTT0025 is co-transcribed as part of the siderophore biosynthesis operon, the same RT-PCR procedure was followed, this time using primers designed to amplify a 1075 bp region bridging FTT0025 and FTT0026. The data presented in Fig. 4 revealed that transcription of mRNA encoding both FTT0025 and FTT0026 was upregulated by $F$. tularensis subsp. novicida U112 under conditions of iron deficiency. As in Fig. 3, controls for RNA normalization and absence of DNA contamination supported this conclusion. This result confirmed that expression of the siderophore biosynthesis operon is upregulated under iron-deficient conditions and, moreover, that FTT0025 is co-transcribed as part of this operon.

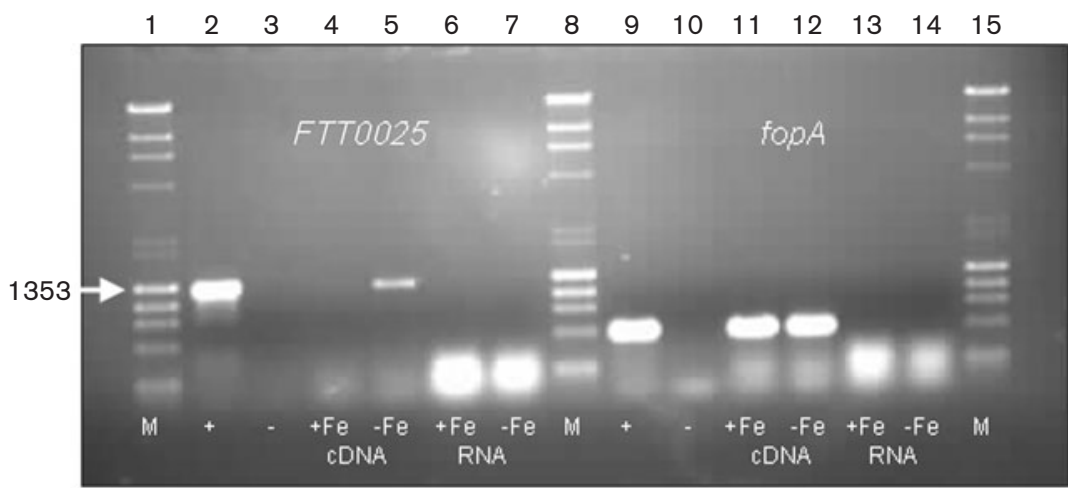

Fig. 3. RT-PCR examination of the expression of FTTO025 by F. tularensis subsp. novicida $\mathrm{U} 112$ in the presence and absence of iron. Lanes: 1, 8 and 15, molecular mass markers; 2-7, amplification of FTTOO25; 9-14, amplification of fopA. Lanes: 2 and 9, genomic DNA positive control; 3 and 10, no-DNA controls; 4 and 11, cDNA from iron-replete conditions; 5 and 12, cDNA from iron-deficient conditions; 6 and 13, RNA from iron-replete conditions; 7 and 14, RNA from iron-deficient conditions. 


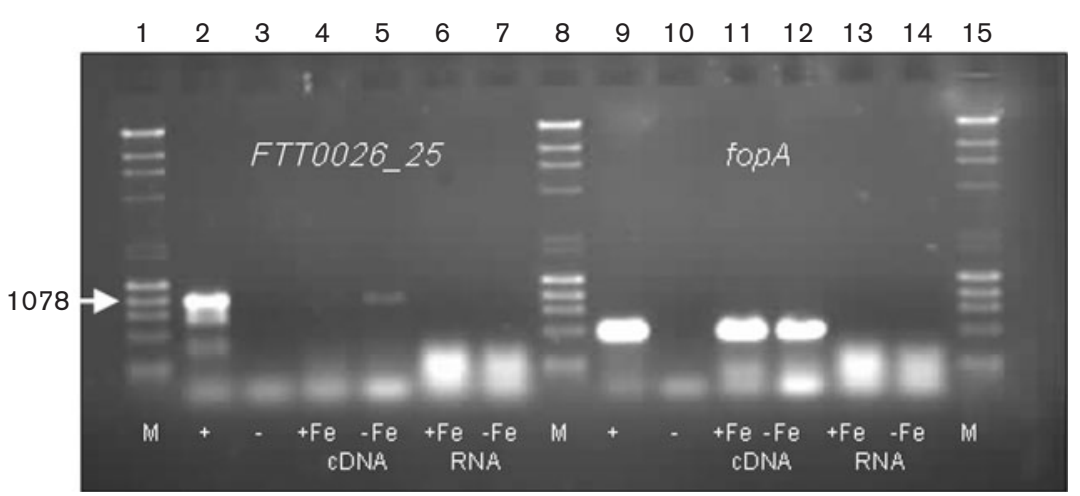

Fig. 4. RT-PCR examination of the co-transcription of FTTO025 and FTTOO26 in F. tularensis subsp. novicida U112 in the presence or absence of iron. Lanes: 1, 8 and 15, molecular mass markers; $2-7$, amplification of fragment bridging FTTOO25 and FTTOO26; 914 , amplification of fopA. See Fig. 3 legend for details of lanes.

\section{Production of the F. tularensis subsp. novicida U112 $\triangle F T T 0025$ mutant}

Having shown that FTT0025 was a member of the siderophore operon, we wanted to determine the role of this gene in siderophore production and/or function. The approach we adopted was to generate a targeted deletion of the ORF of FTT0025 in F. tularensis subsp. novicida U112. An in-frame unmarked $F$. tularensis subsp. novicida U112 $\triangle$ FTT0025 mutant was generated by allelic replacement (see Methods). Of 20 sucrose-resistant colonies, 15 had a mutant phenotype. This deletion phenotype was confirmed by Southern blot hybridization (Fig. 5). Due to the presence of an EcoRV site in the FTT0025 gene, it was determined that a DIG-labelled left flank region probe would hybridize to a $2405 \mathrm{bp} E c o \mathrm{RV}$ fragment of wild-type genomic DNA, whilst this probe would recognize a $2572 \mathrm{bp} E c o$ RV fragment from a genome from which the FTT0025 ORF has been deleted. As shown in Fig. 5, we indeed observed only the $2572 \mathrm{bp}$ fragment in genomic DNA isolated from the presumptive mutant (Fig. 5; lane 3 ), thus confirming the deletion of this ORF in this strain.

\section{Deletion of FTT0025 affects siderophore activity}

The function of FTT0025 is unknown due to the lack of homologues or orthologues of this gene in other bacterial genomes. However, certain sequence elements led to the annotation of FTT0025 as a hypothetical membrane protein. For example, PSORT predicts FTT0025 to be an inner-membrane protein (Huntley et al., 2007). To elucidate further the function of FTT0025, a series of simple characterization experiments were performed in which we compared the phenotype of $F$. tularensis subsp. novicida U112 wild-type and the $\Delta F T T 0025$ mutant. In liquid medium, the $\triangle F T T 0025$ mutant appeared to enter exponential-phase growth more slowly than wild-type, after which its growth in exponential phase paralleled that of wild-type (Fig. 6). In addition, both strains appeared to achieve a similar cell density upon reaching stationary phase. To determine whether siderophore secretion was affected by the deletion of FTT0025, cells were cultured on CAS agar as described previously (Schwyn \& Neilands, 1987). A larger zone of siderophore secretion was produced by the $\triangle F T T 0025$ mutant compared with the wild-type (Fig. 7a). This disparity was observed over the course of 3 days of growth on CAS agar (Fig. 7b), suggesting that deletion of FTT0025 resulted in increased siderophore secretion or an inability to retrieve siderophore back into the cell. These findings, coupled with the predictions of PSORT, suggest that FTT0025 plays a role in siderophore uptake. To date, genes thought of as essential for promoting uptake of iron by bacteria, such as ton $B$, are not found in the Francisella genome. Therefore, FTT0025

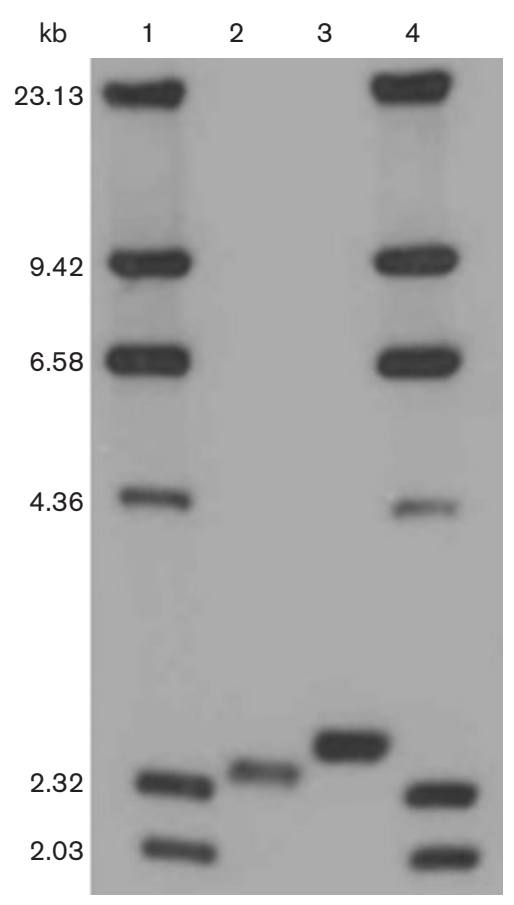

Fig. 5. Confirmation of the targeted deletion of FTTO025 from F. tularensis subsp. novicida U112. DNA isolation and Southern blot hybridization were performed as described in Methods. Lanes: 1 and 4, molecular mass markers; 2, EcoRV digest of wild-type $F$. tularensis subsp. novicida U112; 3, EcoRV digest of $F$. tularensis subsp. novicida U112 2 FTTO025. Expected wild-type band, 2405 bp; expected mutant band, 2572 bp. 


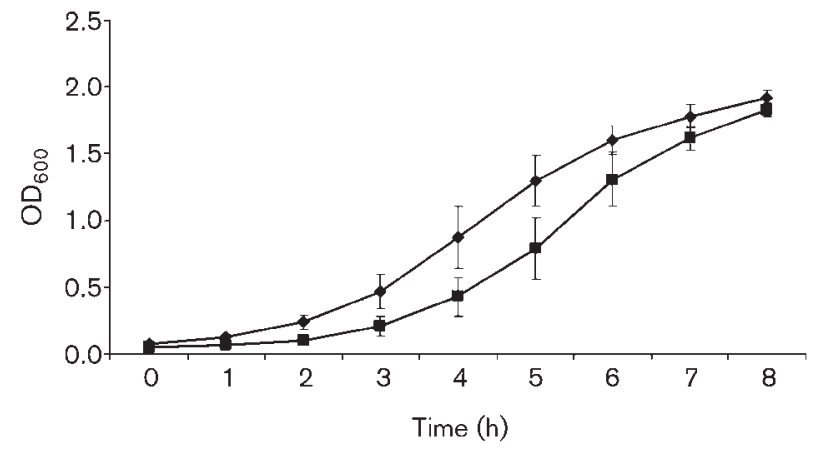

Fig. 6. Dependence of growth of $F$. tularensis subsp. novicida on expression of FTT0025. Growth curves were performed as described in Methods for $F$. tularensis subsp. novicida U112 wild-type $(\Delta)$ and $F$. tularensis subsp. novicida U112 $\Delta$ FTTO025 (घ). The data represent the mean of three separate experiments, with error bars indicating $95 \%$ confidence limits.

may serve this essential function. It is important to note that F. tularensis subsp. novicida U112 2 FTT0025 did reach a cell density similar to that of wild-type, suggesting that other iron-uptake mechanisms are available to the bacteria. As the CAS assay demonstrated, siderophore production and secretion was by no means hindered, confirming that the in-frame deletion of FTT0025 had no upstream effects on the other siderophore genes contained within the biosynthesis operon. It is also possible that the increased siderophore levels we observed related to further upregulation in an attempt to compensate for the lack of uptake.

\section{The F. tularensis subsp. novicida U112 4 FTT0025 mutant is attenuated}

Given the limited availability of iron within the normal hosts of F. tularensis subsp. novicida U112, it was expected that a reduced ability to acquire iron would result in reduced virulence. To test this hypothesis directly, we performed an attenuation study in $\mathrm{BALB} / \mathrm{c}$ mice as described in Methods. The results of this study are summarized in Table 2. All mice challenged via the s.c. route with $10^{3}$ or $10^{4}$ c.f.u. of wild-type $F$. tularensis subsp. novicida $\mathrm{U} 112$ died by day 4 . However, four of the six mice challenged with $10^{3}$ c.f.u. of $F$. tularensis subsp. novicida U112 $\triangle$ FTT0025 survived; this represents a significant level of attenuation $(P=0.0197)$. The MLD for wild-type $F$. tularensis subsp. novicida U112 has been calculated previously to be $3.4 \times 10^{2}$ c.f.u. via the s.c. route in $\mathrm{BALB} / \mathrm{c}$ mice (P. C. F. Oyston, personal communication). However, the MLD of $F$. tularensis subsp. novicida U112 $\triangle$ FTT0025 was calculated as $5.3 \times 10^{3}$ c.f.u. via the s.c. route, corresponding to a greater than 10 -fold increase for this strain. Although two of six mice survived challenge with $10^{4}$ c.f.u. of $F$. tularensis subsp. novicida U112 $\triangle F T T 0025$, this result was not statistically significant $(P=0.0996)$.
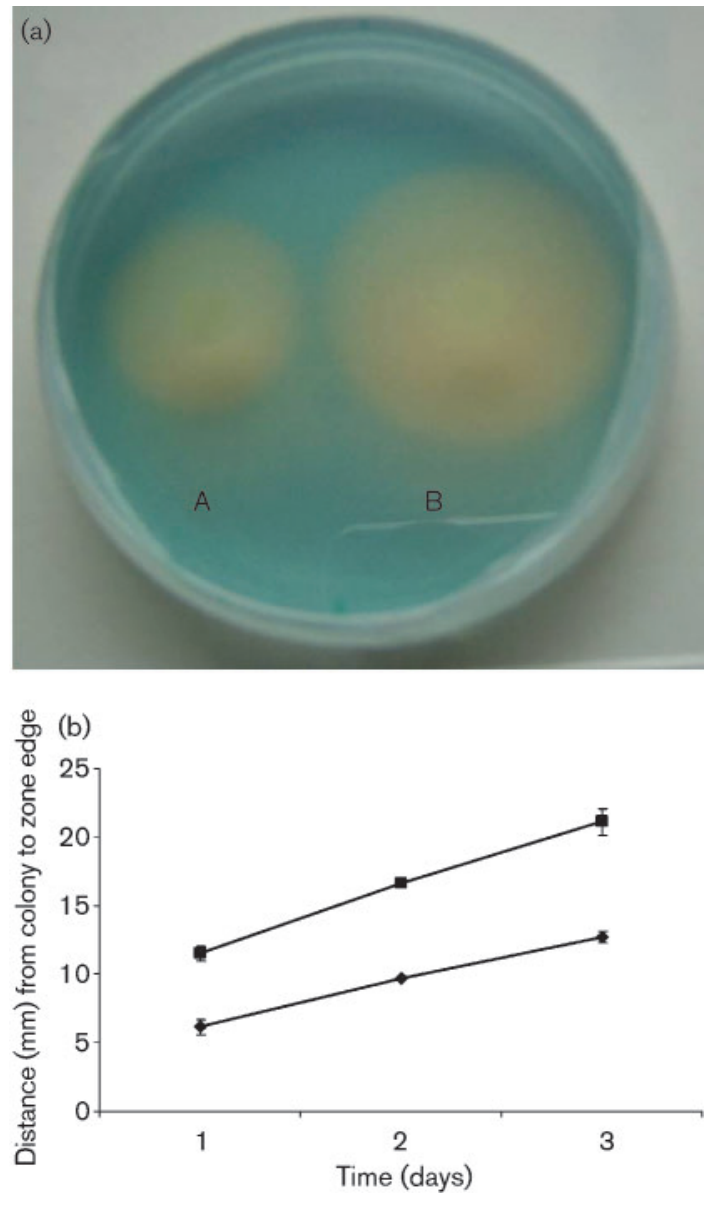

Fig. 7. (a) Siderophore production by $F$. tularensis subsp. novicida U112 wild-type and the $\triangle$ FTT0025 mutant. Colorimetric detection on CAS agar was performed as described in Methods for F. tularensis subsp. novicida U112 wild-type (A) and F. tularensis subsp. novicida U112 LFTT0025 mutant (B). (b) Dependence of secretion of siderophore over time on FTTO025. CAS-based determination of siderophore production was performed as described in Methods for F. tularensis subsp. novicida U112 wild-type $(\boldsymbol{\nabla})$ and $F$. tularensis subsp. novicida U112 FTTO025 mutant ( $\boldsymbol{\square})$. The data represent the mean of three separate experiments, with error bars indicating $95 \%$ confidence limits.

Targeting siderophore receptors has attenuated other bacterial pathogens. In Bacillus anthracis, deletion of the siderophore biosynthesis gene $a s b A$ attenuated virulence in BALB/c mice (Cendrowski et al., 2004). Similarly, alcaligin biosynthesis by Bordetella bronchiseptica was shown to be essential for maximal virulence in a swine infection model (Register et al., 2001). Generating a fepA iron cir triple mutant in Salmonella enterica, each gene encoding a different siderophore receptor, resulted in attenuation, and the mutant was capable of inducing a protective immune response in mice (Rabsch et al., 2003; Williams et al., 2006). 
Table 2. Dependence of virulence on expression of FTT0025 In vivo assessment of virulence was performed as described in Methods.

\begin{tabular}{|lccl|}
\hline Challenge strain & $\begin{array}{c}\text { Dose } \\
\text { (c.f.u.) }\end{array}$ & $\begin{array}{c}\text { No. of } \\
\text { survivors }\end{array}$ & $\begin{array}{c}\text { Time to } \\
\text { death (days) }\end{array}$ \\
\hline $\begin{array}{l}\text { F. tularensis subsp. } \\
\text { novicida U112 } \Delta \text { FTT0025 }\end{array}$ & $4.05 \times 10^{4}$ & $2 / 6$ & $3,4,4,4$ \\
F. tularensis subsp. & $4.05 \times 10^{3}$ & $4 / 6$ & 3,5 \\
novicida U112 & $4.2 \times 10^{4}$ & $0 / 6$ & $3,3,3,4,4,4$ \\
& $4.2 \times 10^{3}$ & $0 / 6$ & $3,4,4,4,4,4$ \\
\hline
\end{tabular}

Although F. tularensis subsp. holarctica LVS is effective at preventing human cases of tularaemia, the lack of a definition for the mechanism of attenuation for this strain has delayed the license of LVS as a vaccine. However, the ability of this attenuated Francisella strain to induce a protective immune response in humans lends promise to the generation of a well-characterized attenuated vaccine. The results from this study show that the previously described Francisella siderophore biosynthesis operon also includes the $55 \mathrm{kDa}$ hypothetical membrane protein FTT0025, which appears to play an important role in siderophore uptake. As observed for a number of bacterial pathogens, deleting this putative siderophore receptor results in a significant loss of bacterial virulence, once again confirming the association between bacterial iron acquisition from the host and establishment of infection. Further work is currently under way to assess the protective efficacy of the F. tularensis subsp. novicida U112 $\triangle$ FTT0025 mutant. Results confirming its suitability as a rationally attenuated protective mutant will lead to the generation of the $\triangle F T T 0025$ mutant in the most virulent subspecies, F. tularensis subsp. tularensis SchuS4.

\section{ACKNOWLEDGEMENTS}

We acknowledge Dr K. Svennson at FOI, Sweden, for the assignation of putative microarray ORFs using GLIMMER. We thank Dr N. Silman and J. Oshota at the Health Protection Agency, Porton Down, UK, and Dr P. Butcher and the rest of the Bacterial Microarray Group at St George's Hospital, London, UK, for printing the Francisella arrays. We express gratitude to R. Dean and Dr M. Nelson for their technical assistance. We thank A. Hunter and Dr T. Laws at Dstl for their kind help with statistical analysis of the data. We also thank Dr M. Bolanowski for his critical reading of the manuscript. This contract has been funded in whole or in part with Federal funds from the National Institute of Allergy and Infectious Diseases, National Institutes of Health, Department of Health and Human Services, USA, under contract no. NO1-AI-50041.

\section{REFERENCES}

Andrews, S. C. (1998). Iron storage in bacteria. Adv Microb Physiol 40, 281-351.
Casadevall, A. \& Pirofski, L.-A. (2004). The weapon potential of a microbe. Trends Microbiol 12, 259-263.

Cendrowski, S., MacArthur, W. \& Hanna, P. (2004). Bacillus anthracis requires siderophore biosynthesis for growth in macrophages and mouse virulence. Mol Microbiol 51, 407-417.

Chamberlain, R. E. (1965). Evaluation of live tularemia vaccine prepared in a chemically defined medium. Appl Microbiol 13, 232-235.

Clarke, T. E., Tari, L. W. \& Vogel, H. J. (2001). Structural biology of bacterial iron uptake systems. Curr Top Med Chem 1, 7-30.

Crosa, J. H. (1997). Signal transduction and transcriptional and posttranscriptional control of iron-regulated genes in bacteria. Microbiol Mol Biol Rev 61, 319-336.

Deng, K., Blick, R. J., Liu, W. \& Hansen, E. J. (2006). Identification of Francisella tularensis genes affected by iron limitation. Infect Immun 74, 4224-4236.

De Voss, J. J., Rutter, K., Schroeder, B. G. \& Barry, C. E., III (1999). Iron acquisition and metabolism by mycobacteria. J Bacteriol 181, 4443-4451.

Forsman, M., Sandstrom, G. \& Sjostedt, A. (1994). Analysis of $16 S$ ribosomal DNA sequences of Francisella strains and utilization for determination of the phylogeny of the genus and for identification of strains by PCR. Int J Syst Bacteriol 44, 38-46.

Golovliov, I., Sjostedt, A., Mokrievich, A. \& Pavlov, V. (2003). A method for allelic replacement in Franciella tularensis. FEMS Microbiol Lett 222, 273-280.

Gurycova, D. (1998). First isolation of Francisella tularensis subsp. tularensis in Europe. Eur J Epidemiol 14, 797-802.

Halliwell, B. \& Gutteridge, J. M. C. (1984). Oxygen toxicity, oxygen radicals, transition metals and disease. Biochem J 219, 1-14.

Huntley, J. F., Conley, P. G., Hagman, K. E. \& Norgard, M. V. (2007). Characterization of Francisella tularensis outer membrane proteins. J Bacteriol 189, 561-574.

Johansson, A., Ibrahim, A., Goransson, I., Eriksson, U., Gurycova, D., Clarridge, J. E. \& Sjostedt, A. (2000). Evaluation of PCR-based methods for discrimination of Francisella species and subspecies and development of a specific PCR that distinguishes the two major subspecies of Francisella tularensis. J Clin Microbiol 38, 4180-4185.

Litwin, C. M. \& Calderwood, S. B. (1993). Role of iron in regulation of virulence genes. Clin Microbiol Rev 6, 137-149.

Machuca, A. \& Milagres, A. M. F. (2003). Use of CAS-agar plate modified to study the effect of different variables on the siderophore production by Aspergillus. Lett Appl Microbiol 36, 177-181.

Pelicic, V., Reyrat, J.-M. \& Gicquel, B. (1996). Expression of the Bacillus subtilis sacB gene confers sucrose sensitivity on mycobacteria. J Bacteriol 178, 1197-1199.

Petersen, J. M. \& Schriefer, M. E. (2005). Tularemia: emergence/reemergence. Vet Res 36, 455-467.

Rabsch, W., Methner, U., Voight, W., Tschape, H., Reissbrodt, R. \& Williams, P. H. (2003). Role of receptor proteins for enterobactin and 2,3-dihydroxybenzoylserine in virulence of Salmonella enterica. Infect Immun 71, 6953-6961.

Ratledge, C. \& Dover, L. G. (2000). Iron metabolism in pathogenic bacteria. Annu Rev Microbiol 54, 881-941.

Reed, L. J. \& Muench, H. (1938). A simple method of estimating fifty per cent endpoints. Am J Epidemiol 27, 493-497.

Register, K. B., Ducey, T. F., Brockmeier, S. L. \& Dyer, D. W. (2001). Reduced virulence of a Bordetella bronchiseptica siderophore mutant in neonatal swine. Infect Immun 69, 2137-2143.

Sambrook, J., Fritsch, E. F. \& Maniatis, T. (1989). Molecular Cloning: a Laboratory Manual, 2nd edn. Cold Spring Harbor, NY: Cold Spring Harbor Laboratory. 
Schwyn, B. \& Neilands, J. B. (1987). Universal chemical assay for the detection and determination of siderophores. Anal Biochem 160, $47-56$.

Stewart, G. R., Wernisch, L., Stabler, R., Mangan, J. A., Hinds, J., Laing, K. G., Young, D. B. \& Butcher, P. D. (2002). Dissection of the heat-shock response in Mycobacterium tuberculosis using mutants and microarrays. Microbiology 148, 3129-3138.

Sullivan, J. T., Jeffery, E. F., Shannon, J. D. \& Ramakrishnan, G. (2006). Characterization of the siderophore of Francisella tularensis and role of $f_{s} l A$ in siderophore production. J Bacteriol 188, 3785-3795.

Thomas, R. M., Titball, R. W., Oyston, P. C., Griffin, K., Waters, E., Hitchen, P. G., Michell, S. L., Grice, I. D., Wilson, J. C. \& other authors (2007). The immunologically distinct $O$ antigens from Francisella tularensis subspecies tularensis and Francisella novicida are both virulence determinants and protective antigens. Infect Immun 75, 371-378.

Whipp, M. J., Davis, J. M., Lum, G., de Boer, J., Zhou, Y., Bearden, S. W., Petersen, J. M., Chu, M. C. \& Hogg, G. (2003). Characterization of a novicida-like subspecies of Francisella tularensis isolated in Australia. J Med Microbiol 52, 839-842.

Williams, P. H., Rabsch, W., Methner, U., Voigt, W., Tschape, H. \& Reissbrodt, R. (2006). Catecholate receptor proteins in Salmonella enterica: role in virulence and implications for vaccine development. Vaccine 24, 3840-3844.

Wooldridge, K. G. \& Williams, P. H. (1993). Iron uptake mechanisms of pathogenic bacteria. FEMS Microbiol Rev 12, 325-348. 